\title{
High-Rise Dominants in the Urban Landscape of Baghdad Architecture and Composition
}

\author{
Sumayah Layij Jasim ${ }^{1, *}$ \\ ${ }^{1}$ Department of Urban Studies and Theory of Architecture, Mayoralty of Bagdad, Design Department, Bagdad, Iraq \\ "Corresponding author.Email: sumaya_arch@yahoo.com
}

\begin{abstract}
The placement of high-rise dominants in the structure of large cities has become a hallmark of modern urban transformations in the face of active urbanization. High-rise dominants can greatly benefit a city where they can enhance its value and express its development and the strength of its economy, as well as provide functions that distinguish it locally and globally, if they are well planned and designed, they can create an image of a dynamic, a prosperous, sustainable city, attractive for life and work.

The article is devoted to the study of architectural and compositional features of the formation of highrise dominants in the urban landscape of Baghdad - the capital of Iraq and one of the largest cities in the Middle East. The architecture of high-rise buildings has special, specific features that are reflected in the composition and appearance of buildings and complexes. The author has identified the following features: architectural verticals dominate over the low floodplain landscape and low-rise background buildings; have a dominant "The traditional Arabic city accent"; are city-wide landmarks, together with a network of transport highways and areas, they create the planning structure of the city. The article proposes a classification of high-rise buildings - compositional dominants, justified by the analysis of existing high-rise buildings in various areas of the city with their central, coastal, middle and marginal locations.
\end{abstract}

Keywords: high-rise dominants, urban landscape, architecture, identity, image of the city

\section{INTRODUCTION}

High-rise dominants are powerful in their form and height architectural dominants with the structure of the city. Their influence on the development of the planning structure is twofold. On the one hand, they provide spatial orientation to residents and visitors of the city, visually directing to public spaces and attractions. On the other hand, the spacious buildings do not alleviate the perception of the already existing buildings adjacent to them. The second aspect of influence - high-rise dominants (HD), in many cases is a negative factor, this is especially noticeable in cities with historically developed buildings. About the object of study, Baghdad was selected. The city is located on the eastern and western side of the Tigris River, which is (the heart of the capital of Baghdad) and (the central business district), high-altitude dominants were chosen in four historical districts of Baghdad (Kadhimiya, Adhamiya, Karkh and Rusafa). In the course of the study, in order to determine the interaction strategy of high-rise dominants with the urban landscape, the following methodological approach is used:
- The first stage is the translation of the analytical model for placing high-altitude dominants in the structure of the city into a practical work project.

- The second stage is the determination of the spaces of the structure of the historical center of Baghdad, which is located on the floodplain banks of the Tigris River and is divided by the river into two parts: Rusafu - located on the eastern shore, the largest part of the city and Karkh - the western part of the city, coastal territories as banks of the Tigris River is the main natural landscape dominant of the city of Baghdad, the territory of new construction as the reconstruction of the territory of new construction around Baghdad, which is called "Baghdad Belt".

- At the last stage, the further mechanism for the formation of high-rise buildings is the harmonious spatial and planning development of the city, the creation of a comfortable, large- 
scale human urban environment. Therefore, the issue of urban landscape formation in interaction, and possibly under the influence of high-rise buildings, is relevant for the development of these cities.

In the context of this study, the urban landscape is considered from the perspective of landscape urbanism [1],[2], as an integrated natural-urbanized system that creates a holistic image of the city - the dynamic interaction of the urbanized spatial planning framework with the natural landscape or artificially created landscape system of the city. Therefore, the objective of the study is to analyze the influence of high-rise buildings on the formation of the urban landscape.

\section{PROBLEMS OF PLACING HIGH-RISE DOMINANTS IN CITIES OF THE MIDDLE EAST WITH A HISTORICALLY DEVELOPED SPATIAL PLANNING STRUCTURE}

In the countries of the Middle East, there is currently a surge in the construction of high-rise buildings in both Istanbul (Turkey) and the city of Dubai (UAE). In these countries, the unreasonable placement of high-rise dominants in the city structure in other cases can adversely affect the morphology of urban fabric, and subsequently the functional and spatial development of the planning structure of these cities ("Fig. 1").

Another problem of placing high-rise dominants of public, business, commercial importance, multifunctional, cultural, and other centers is spatial tolerance to objects of culture and religion, to which residents of Middle Eastern cities treat with great respect and respect ("Fig. 2"). The problem of placing high-rise dominants near the mosques of the city is very acute, since at present there are no administrative regulations and town-planning norms justifying the parameters for the mutual placement of these objects (a skyscraper - a mosque) in order to support and respect the local religion, culture and identity of residents [2]. An example is the golden mosque with the mausoleum of Musa Al-Kazimiyya in the 16th century and the Abbasid Palace, Baghdad, Al-Mustansir Madrasah, late 12 th - early 13 th century, $1233 \mathrm{~g}$, in Baghdad.

The historical feature of Baghdad is the formation of the city in conjunction with its landscape principle (the formation of the geography of the plan), therefore, for the further formation of the landscape of the city, the creation of a unique memorable panorama of the city along its main landscape dominant of the Tigris River is important.

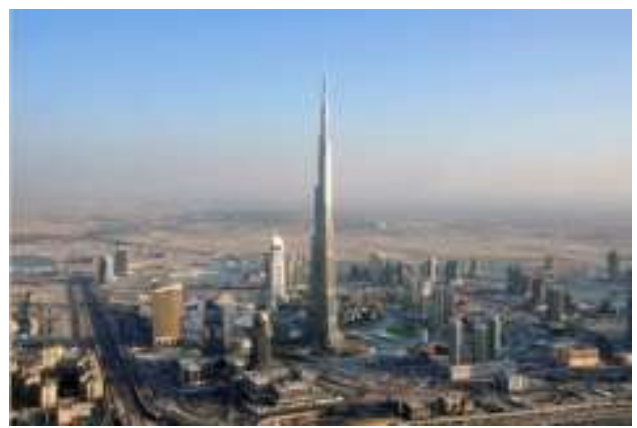

Fig. 1. Dubai Tower (UAE) (the tallest skyscraper in the world) Reference: [16] There is no clear rhythm of tall buildings, there is no harmony in the city skyline of Dubai on urban fabric, as the city's relief is flat.

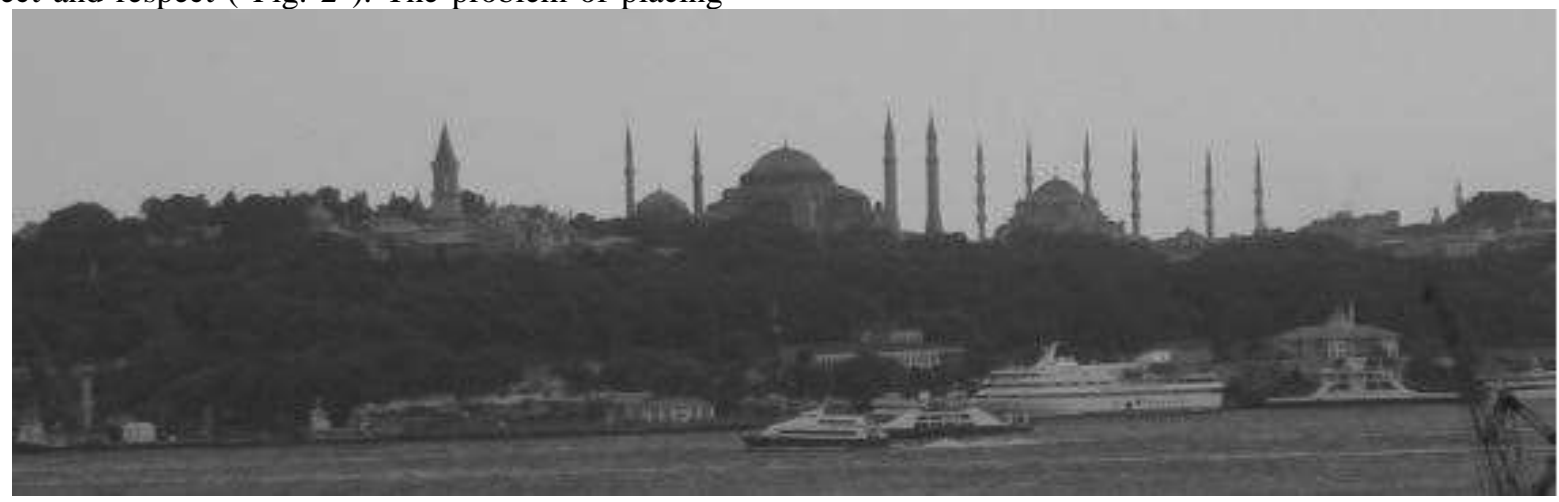

Fig. 2. The image of the historical skyline of Istanbul is dominated by minarets and domes.

The influence of the placement of high-rise dominants on the urban landscape for the city of Baghdad must be considered in conjunction - the mutual influence of the following main factors ("Fig. 3"):
Source:: https://www.irbnet.de/daten/iconda/CIB17649.pdf

- Socio-economic prerequisites for placing a high-rise dominant - the impact on urban development of the city - agglomeration region - country (HD) 
- Environmental consequences of the placement of a high-rise dominant (local aspect territorial aspect)

- Physical effects on the geomorphological and geological structure of the territory of the (HD) and adjacent territories (determination of the level of deformation and radius of impact from the construction of the HD (high-rise dominant)
- Aesthetic impact on the formation of a stable, comfortable and friendly environment in the area of the (HD) (high-rise dominant)

- $\quad$ Mental impact (acceptance or rejection of (HD) by city residents)

- Interaction with public spaces of various functional purposes.

- Natural and climatic changes due to the construction of the (HD) (high-rise dominant)

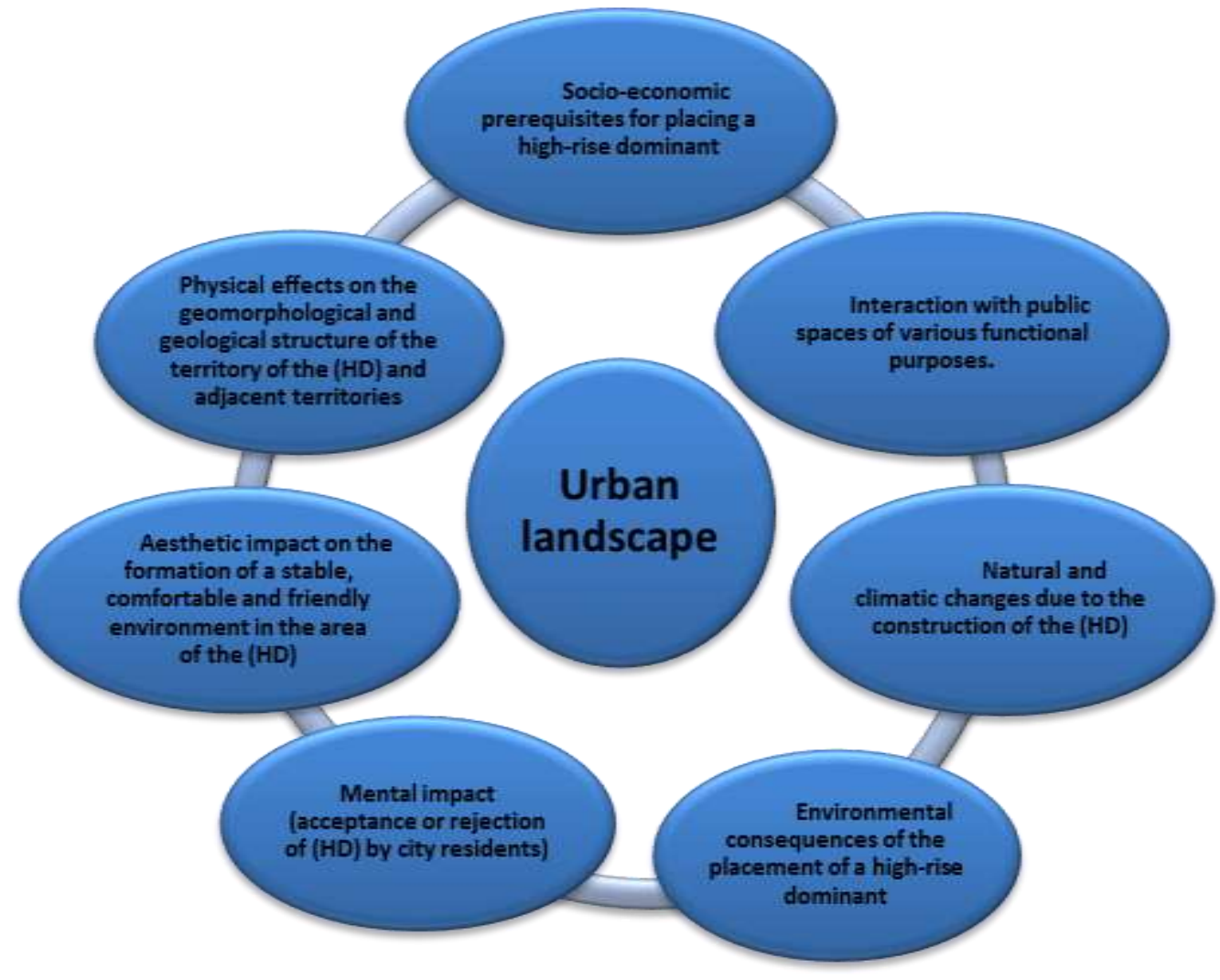

Fig. 3. The effect of the placement of high-rise dominants on the urban landscape.

It is obvious that high-rise objects will continue to be actively built in the largest cities, therefore, it is necessary to develop parameters and recommendations for the placement of high-rise dominants in the structure of cities that have a historically developed spatial planning structure. In the continuation of this study, it is necessary to identify the influence of highrise dominants on urban fabric in terms of the value of its visual characteristics.

The formation of the image of the urban landscape is associated with the image of local places, namely public spaces, which can be formed by high-rise buildings [4], such as the Agbar tower (architect J. Nouvel) in Barcelona. This is a very positive example of the location of the building in the structure of the city, since the tower has become one of the symbols of Barcelona, a spatial reference, and also a catalyst for urban planning reconstruction of the surrounding territories ("Fig. 4"). 


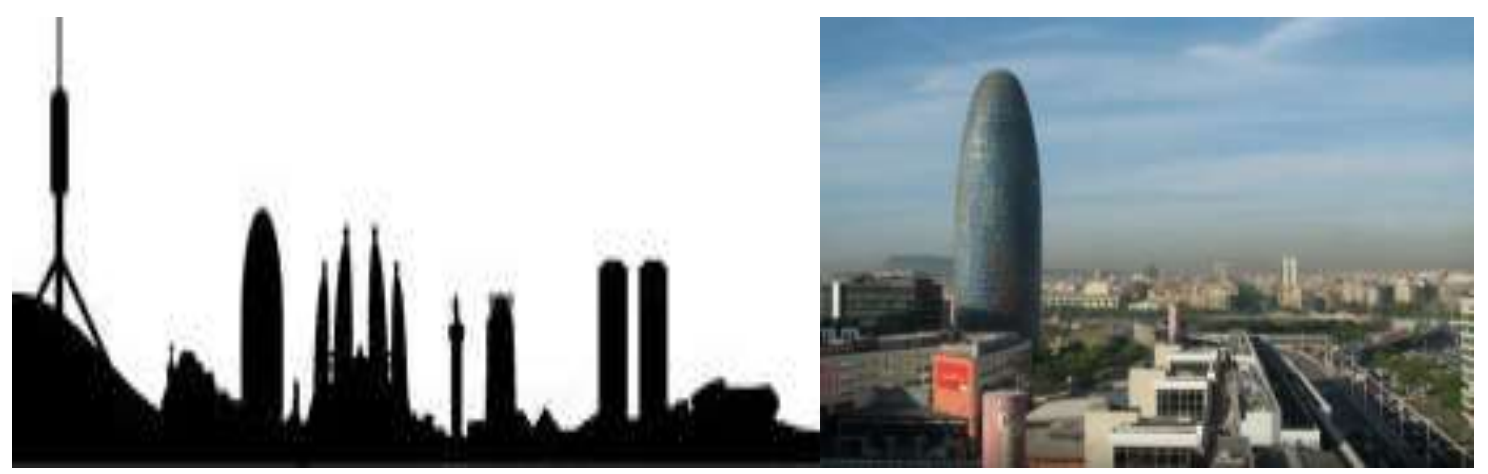

Fig. 4. The influence of the city's silhouette on its image in the context of the formation of the urban landscape of Barcelona.

\section{FEATURES OF HIGH-RISE DOMINANTS IN BAGHDAD}

\section{A. Permeability of urban fabric and the combination of old and new buildings}

Since the coherence of the urban structure is achieved in the context of high-rise buildings in cities in terms of achieving permeability and the connection of the old with the new.

\section{1) Permeability}

This is achieved by reducing the size of the building, adopting a hierarchy in the general layout and isolating the movement of cars and pedestrians so that this does not affect the fabric in which the old high-rise dominants are located [11].

2) Combining the old with the new building

While the connection of the old (existing urban construction with the new) (high-rise buildings) shows how to achieve interaction between them.

- The urban fabric that surrounds the building under construction consists of a tall building in the growth center and on the other side of a low building, so the construction of a new building will be of medium height between them.

- Adding high-rise dominants to an urban image that contains high-rise dominants, where the two sides have the same height, adding a new building should be at the same height.

- The urban fabric that surrounds the building, on the one hand, is a tall building, on the other hand, which separates it from the building, there is a street, there is a low building, the base of the new building will have a low height equal to the height of the opposite building, and that the tower will be bent back from the street and equal to the building next to it.

- Urban fabric contains a landmark or historical or historical building, the need to return a new building to be added to the back so as not to affect the image of the city image of the city.

\section{B. Skyline}

The skyline is the physical embodiment of the reality of urban life. It is also the artistic and aesthetic work of man, which is influenced by environmental conditions.

The city of Baghdad is located on both sides of the Tigris River, as a rule, it is flat and does not contain any natural elevations. Previously, the region's horizon was in harmony with the flat terrain ("Fig. 5"). There is currently no such harmony.

Where the flat sky line of the city of Baghdad began to change between (1936-1956) years, the city of Baghdad turned into a hybrid city from the dominance of domes and lighthouses of mosques to the introduction of some relatively tall buildings within the skyline.

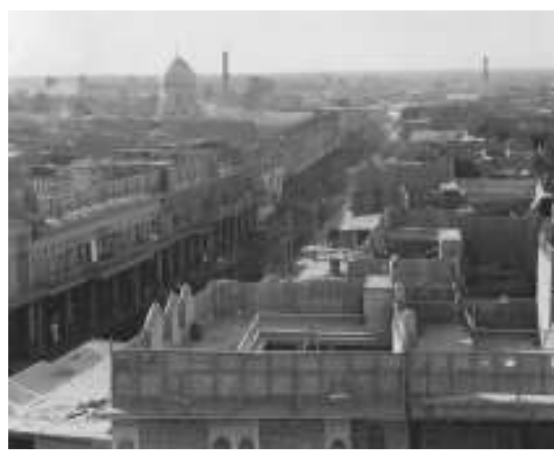

Fig. 5. The skyline of Baghdad - Al-Rasheed street -in 1920 appears clear, in which we see low buildings and the dominance of lighthouses and domes of mosques on the horizon [15].

Source:https://en.wikipedia.org/wiki/Al_Rasheed_Street\#/media/File:Baghdad LOC_13186.jp 


\section{High-rise dominants and the view from them on the panorama of the city}

The height of buildings in Baghdad varies from one district to another depending on the width of the street and the area of the land on which the building is built. These determinants were established by the Baghdad Municipality to control the height of buildings in the region. Al-Khalifa Street and Al-Rashid Street, the height of the buildings varies from two to four floors, provided that the fourth floor extends from the facade, and there are tall buildings overlooking Al-Rashid Street, built in the past. As for buildings with a height of more than eight floors, they were built in previous periods without any control ("Fig. 6").

To achieve the appropriate visual perception between new high-rise buildings and existing ones, the following steps must be performed:

- Application of control of high-rise dominants and the transition from high-rise buildings to low.

- The construction of high-rise dominants or a group of high-rise dominants should correspond to a certain panorama of the city.

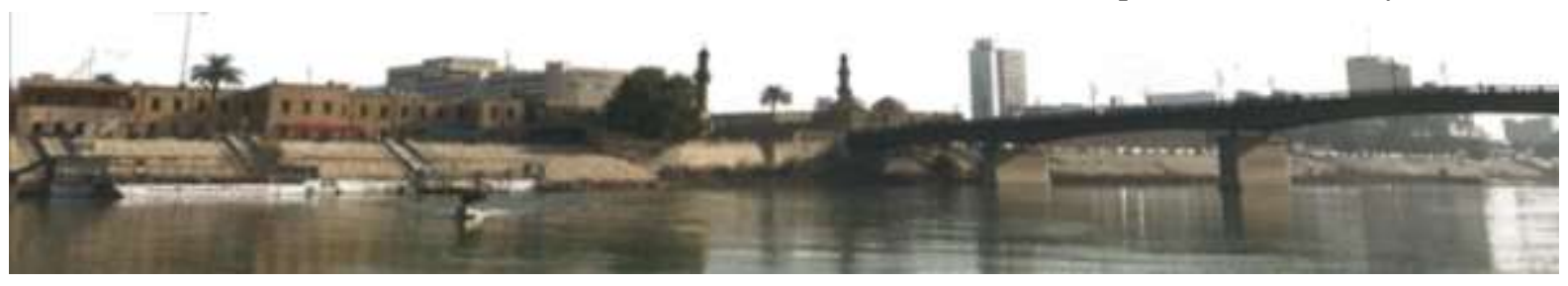

Fig. 6. Inconsistent placement of modern HD in the traditional historical fabric of the city of Baghdad, Karkh district.

\section{Placement of high-rise buildings}

In the construction of high-rise dominants, various methods are used, such as the dominant elimination of an old building and the construction of a high-rise building in its place, as well as other cases, such as the creation of projects on the outskirts of cities, as well as on the Tigris River.

Offer two types of accommodation for high-rise dominants in cities such as Baghdad: the first type is a center for high-rise dominants, and the other is a street for high-rise dominants ("Fig. 7").

1) Center for high-rise dominants (focus)

Features of the location of tall dominants in the center
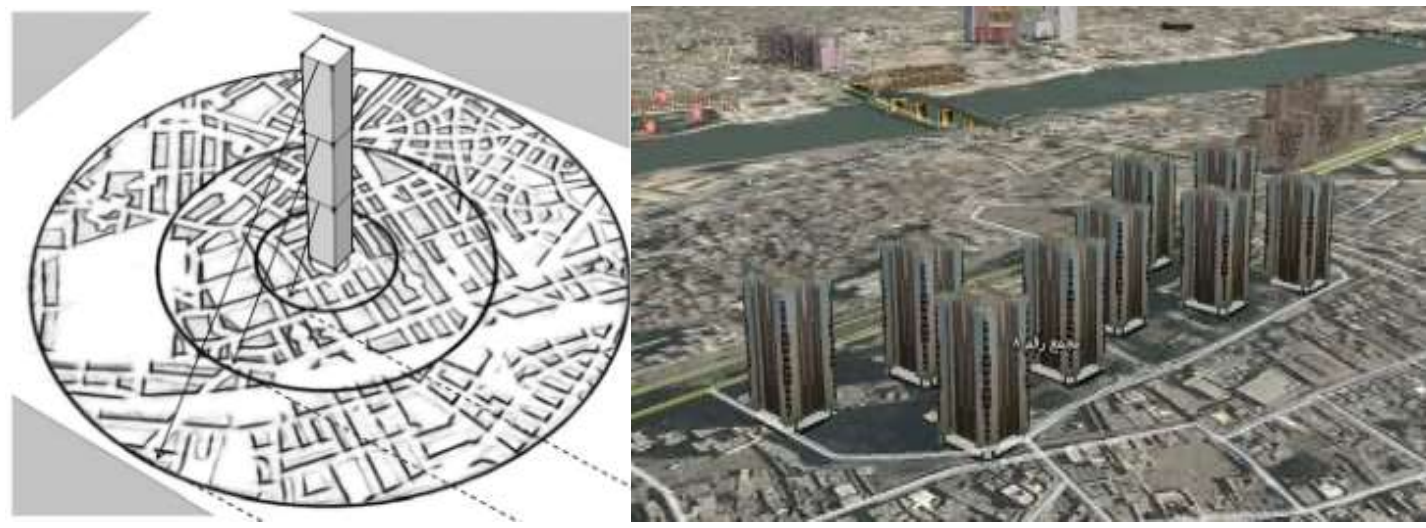

Fig. 7. Offer two types of placement of high-rise dominants in cities such as Baghdad.

Source: https://issuu.com/turath/docs/baghdad_21st_ _ revival_of historic p.44-45 .

Often high-rise dominants are located in the city center, having symbolic and aesthetic goals, since they represent a landmark and an important point in the city, and are considered a development project. If they are designed and planned intentionally, this leads to the development and promotion of the surrounding view.

2) Street for high-rise dominants (axis)

High-rise dominants are adjacent to each other, whether it is one project group of residential towers on one site or next to it on the sides of the street, leaving no space between the buildings and some of them or between buildings and the street through the work of the rebound building a line from the border of the road and this the prevailing model in most areas in cities Existing and old in particular. 
Identifying opportunities for expanding tall buildings inside and outside the center of Baghdad old city, the following:

Expansion within the existing center by replacing and resuming activities or intensifying land use by adopting urban expansion of the city.

Creation of a new secondary center outside the old center, and this will be done in accordance with the following:

- Mixed use development center: where highdensity buildings are created for placement within urban centers.

- The concept of exploitation of emptiness: it is necessary to exploit emptiness in road networks and public transport methods or, in a clearer sense, to use the rights to emptiness in relation to sites owned by private individuals and private persons or official authorities of a city or state in the work of huge development projects with mixed using.

\section{E. Forms of high-rise dominants}

Forms of high-rise dominants should fit into the landscape, adapt to it, improving it visually, adding dynamism, expressiveness, expression or neutrality to it, depending on the city-planning situation.

The spatial form of the high-rise dominants of Baghdad consists of three parts ("Fig. 8"), namely:

- Upper part: the design of the upper part, including the upper surfaces, communication blocks, rest areas, thanks to the shape of the tower block and the use of materials.

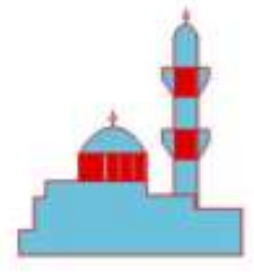

Dome

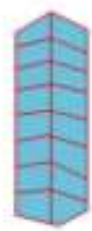

Box

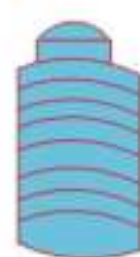

Rotunda
- The intermediate part: the location, size and direction affect the visibility of the sky, because it is reflected in the surroundings, where the design of the building should take these issues into account.

- Base: the lower floors are referred to as the main building. The role of the main building is to create a structure for the public sphere and entrances and help create an attractive world that provides a safe and pedestrian experience. This experience is interesting and convenient. The building should support neighboring streets, public gardens and open spaces on an appropriate scale and integrate the building with adjacent neighboring buildings.

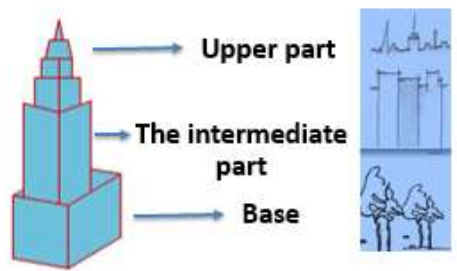

Fig. 8. Parts The spatial form of the high-rise dominants of Baghdad.

At the first stage, high-rise buildings are built in the form of domes and special structures for minarets are used, and the properties of bricks are taken into account when constructing each of the mosques and schools. As for the second stage, this period is very important in the history of architecture of Baghdad, and this is due to its design, worthy of reflection "in terms of its highly professional architectural solutions" ("Fig. 9").

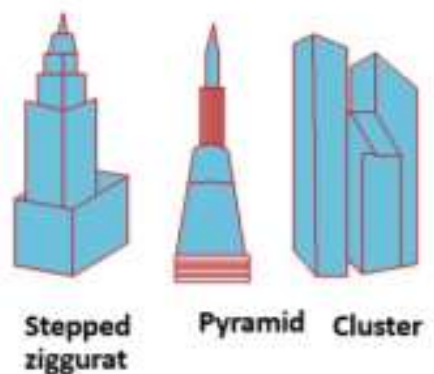

Fig. 9. Forms of high-rise dominants and their influence on the skyline of Baghdad.

\section{F. The color value of high-rise dominants}

This problem emphasizes the importance of color, because the enormous size of tall structures requires decisions not only in shape, space and weight, but also in color, since the perception of a tall building will be easier when its optical density is very different from the optical density of the sky, and when it has the same density, the color will differ between them.

In Baghdad, the blue color of the outer surfaces was already used in the $10^{\text {th }}$ century as a background for 
domes of mosques, schools and shrines. The blue color served as the basis for the remaining colors, which began to form the external inscriptions of the dome. Yellow, with its expressive meanings, is one of the most used colors for decorating the dome surfaces, and the use of white and black, which are two colors, help to identify motifs and patterns, as they indicate the sequence of night and day and the continuity of life. Gold color was used to cover some domes of buildings that were of religious importance (Golden Mosque with the mausoleum of Musa Al-Kazimiyya). Green color was also used for domes of some religious buildings (mosques, schools). Beige, which is an expression of the earth on the largest scale and a person on a smaller scale, as if mosques and schools, distinguished by their domes, are a sign of life in the desert, as well as religious influence in the color of the green dome.

\section{Classification OF HIGH-RISE DOMINANTS OF BAGHDAD}

In the center of Baghdad there are many historical sights and historical quarters, as well as multi-storey modern buildings for business and public purposes. The old city center is part of the central business district of Baghdad, and its planning structure is represented by a combination of old and modern buildings. An analysis of the distribution of high-rise dominants in the structure of Baghdad, which influence the formation of the structure of the urban landscape, made it possible to distinguish them into 4-groups: The first group of highrise dominants - historical Islamic buildings and structures - these are objects associated with the traditional religion, spirit, thoughts and religious beliefs of society, their spiritual character depends on the centuries-old architecture of Islamic mosques, minarets. These buildings and structures are now not only the architectural, historical and cultural attractions of Baghdad, but also a place to meet the religious needs of representatives of the Islamic community. An example of this group is the Golden Mosque with the Mausoleum of Musa Al-Kazimiyya ("Fig. 10").

- The 2nd group of high-rise dominants historical monuments and memorable places are elements of the formation of symbols of the intellectual, spiritual life of a person and the stages of the historical development of society. In each square of Baghdad, there is a monument placed to a famous historical person or associated with certain historical events; Freedom Monument, etc. ("Fig. 11").

- The 3rd group of high-rise dominants historical Public buildings and architectural and landscape complexes - are represented by archaeological and historical-architectural complexes of world and national cultural heritage. An example of this group is Baghdad Mall, multifunctional ("Fig. 12").

- $\quad$ The 4th group of high-rise dominants - modern buildings - icons - these are high-rise buildings, architectural complexes and centers of multifunctional, commercial, business, cultural and other purposes, which are aesthetic architectural symbols - brands of modern Baghdad. Buildings - icons of modern Baghdad - Hotel Babylon ("Fig. 13").

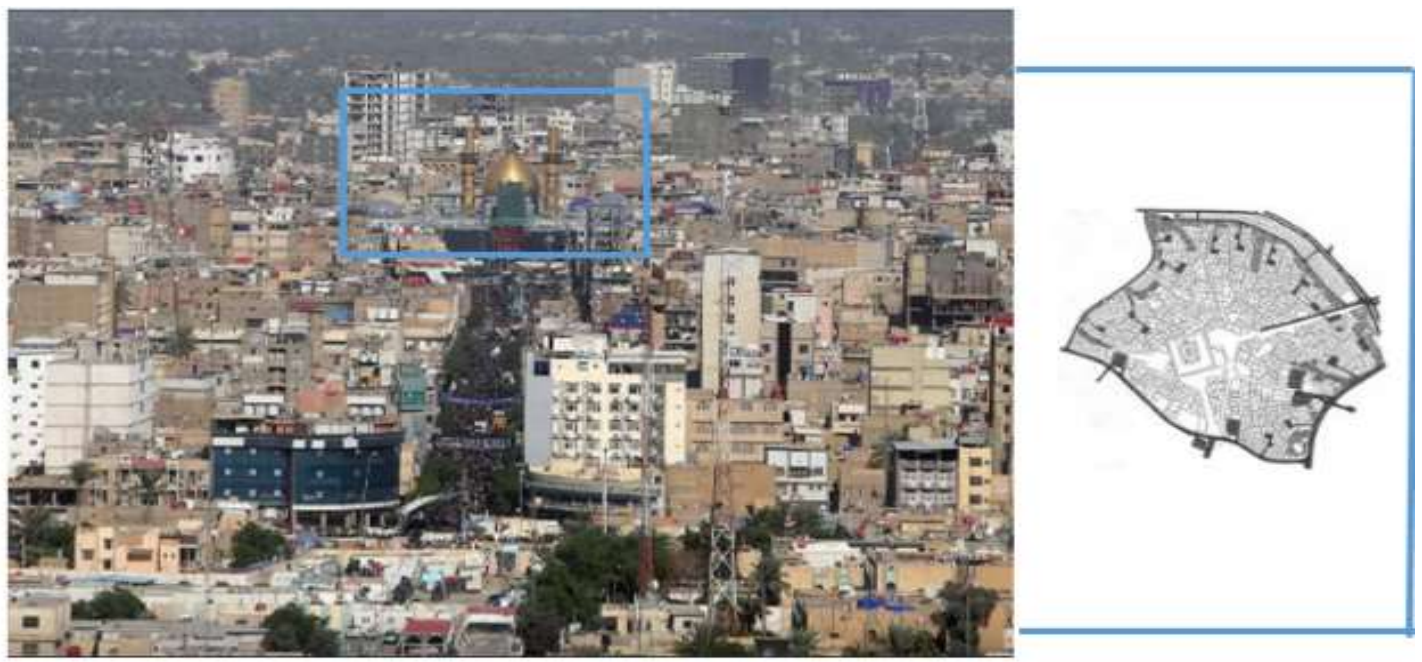

Fig. 10. Golden Mosque with the Mausoleum of Musa Al-Kazimiyya, X - XVI c: Aerial view showing the attitude of the building to the microdistricts and the general urban view of the object. Area: 60,000 m2. , height: $34 \mathrm{~m}$., this building is a restoration of Shah Ismail I (1502). 


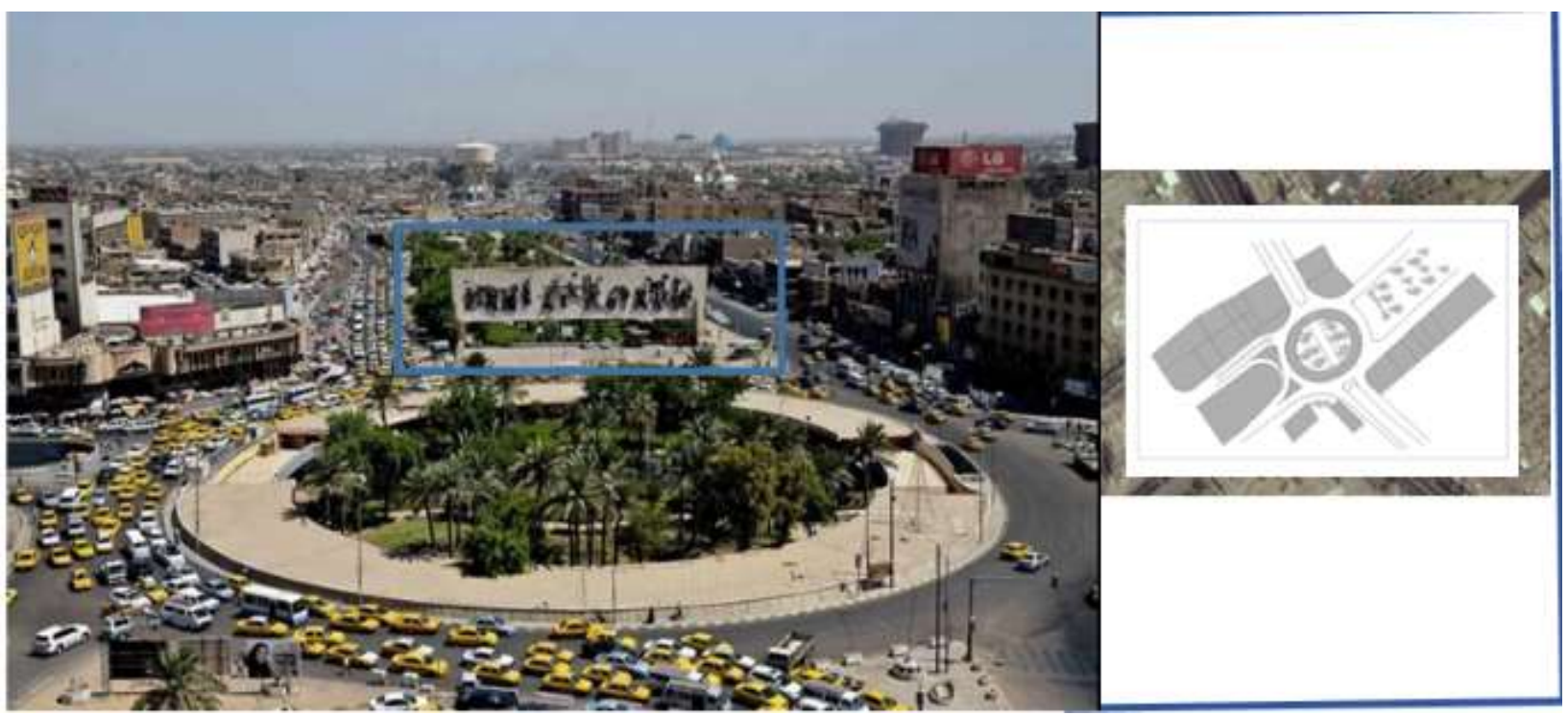

Fig. 11. Freedom Monument (1961): Aerial view showing the relation of the monument to the microdistricts and general urban view. Area: - $2000 \mathrm{~m} 2$ , height: $-10 \mathrm{~m}$. Designed and executed by Iraqi artist Jawad Salim in collaboration with architect Rifaat Al-Jadraji.

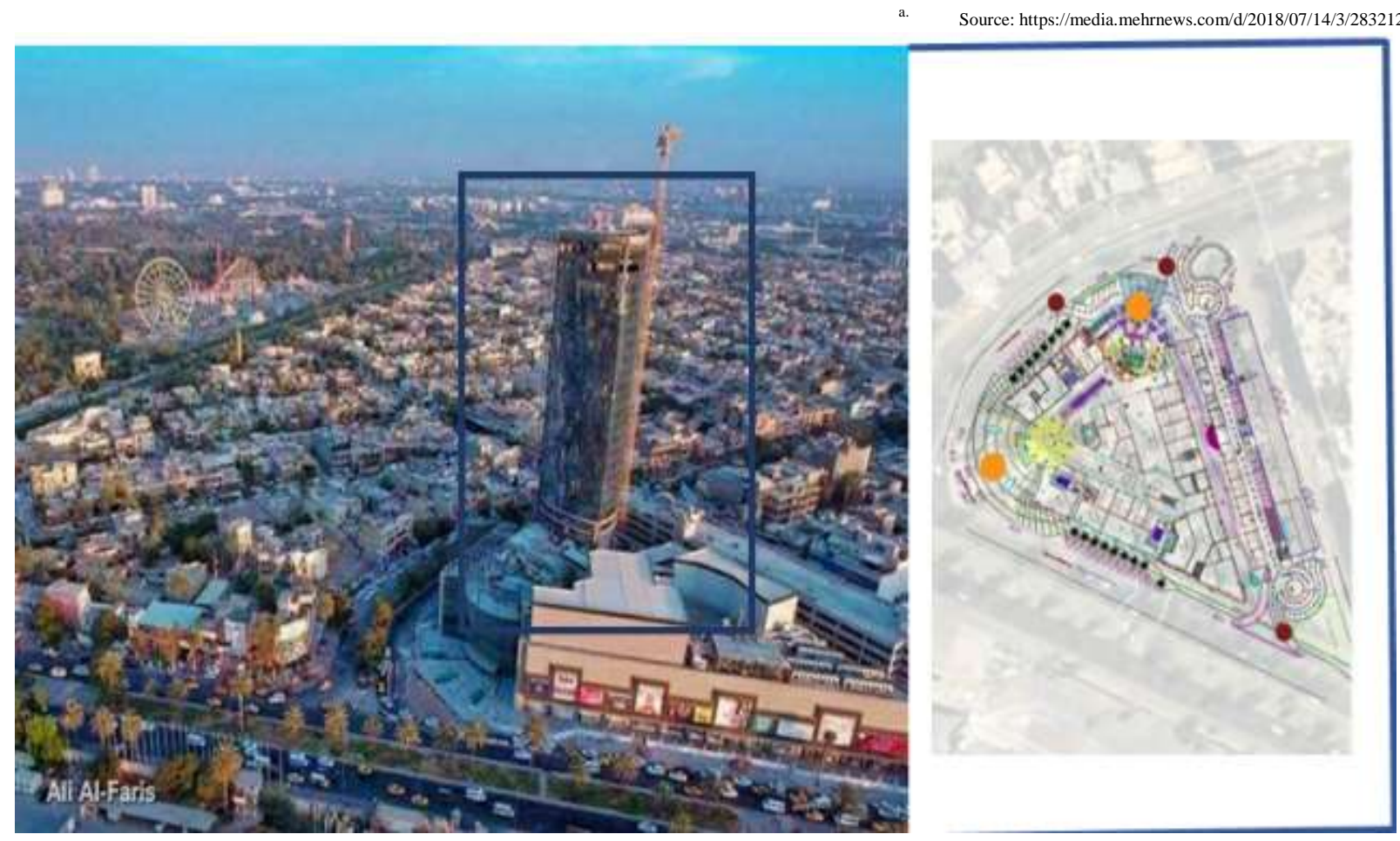

Fig. 12. Baghdad Mall 2017, multi-functional: Aerial view showing the attitude of the building to the micro districts and the general urban view, area: 80000 m2, Height: 120 m. Design byTeverum Turkish Construction Company. 


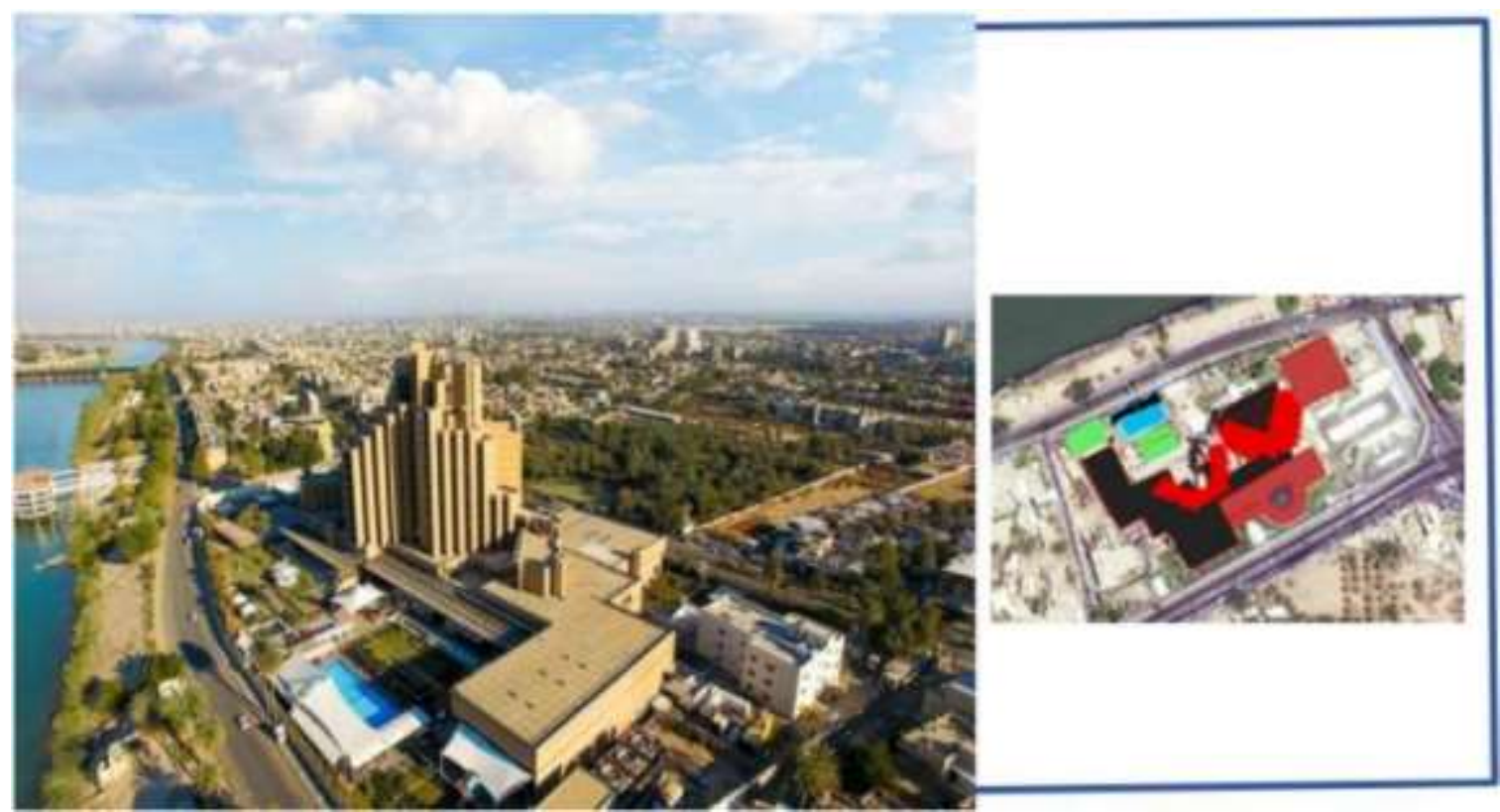

Fig. 13. Babylon Hotel 1982: Aerial view showing the attitude of the building to the neighborhood and general urban view, area: $80,000 \mathrm{~m} 2$, Height: 170 m. Architect Edward Ravenkar (Slovenia).

\section{CONClUSION}

The high-rise dominants discussed in this article are not just skyscrapers that claim to be the new modern symbols of cities. Their appearance was caused by a wide variety of local and global motivations and is explained by urban regulatory considerations.

The strategy for the formation of vertical dominants is based on the principles of sustainable development of the urban environment. The presented analysis showed that an innovative approach to designing memorable high-rise buildings integrated into the historical landscape is based on the search for a unique combination of non-standard elements in structural systems, functional and planning characteristics, construction and finishing materials, related to the geographical location of the object.

High- rise dominants are buildings whose height is distinct and clear in an urban environment, and it has a clear effect on the horizon, since it is the most visible gate to space and time, affecting the height of the sky.

The importance of high- rise dominants is also evident in the urban system, since high-altitude dominants are vital in an important topic for each city, especially Baghdad, for the historical part, seeking to find a special place for it in a successful planning policy, with an emphasis on the architectural and compositional features of the formation of high- rise dominants in the urban landscape for Baghdad, where high-rise dominants are a symbol of the values of
Source: https://media-cdn.tripadvisor.com/media/photo-s/10/42/17/27/babylon-warwick-hotel.jpg decision makers in the past and present, they are symbols of the city. A tall building is an important element the horizon because the building is the most unique and dominant in the city in terms of visibility through streets, intersections and points of view.

General recommendations:

- The need to inform the public on the part of the government and those involved in the modernization of the characteristic high-rise buildings in general and of a landmark nature, in particular in the city of Baghdad, and working to present them as an advantage for the city.

- See the negative effects that were detected locally in high-rise dominants, and try to reduce these effects.

- Emphasizing that high-rise dominants do not depend on their formal characteristics and symbolic significance, but on the degree of their success in achieving urban integration.

\section{References}

[1] E. Krasilnikova. Landscape urbanism. Theory = Practice. Part Scientific and practical foundations of landscape urbanism. "Regional news." 2015. p. 19.[in Russian].

[2] S.L. Jasim and E. Krasilnikova. Influence of high-rise dominants on the structure of the urban landscape. Publication Institute of the CIS countries. Russian University of Transport 
(MIIT). Russian Academy of Engineering (RAE). 2019 (1). № 3. p. 2 -3.[in Russian].

[3] G. Ptichnikova. New century high risers in the core areas of historic cities in Russia. Procedia Engineering, 2016, № 165, pp.1903-1910.

[4] K. Lynch. The Image of the City, MIT Press, 1960. pp.141-142.

[5] J.Corner and A.Bick Hirsch. The landscape imagination. Collected Essays of James Corner 1990-2010 // Princeton Architectural Press. New York. 2014, pp.111-127.

[6] Kheir Al-Kodmany. The Logic of Vertical Density: Tall Building in the 21stCentury City/ International Jornal of HighRise Buildings, Vol 1, No 2,June 2012, pp.131-148

[7] Al- Kodmany, Kheir and Ali, Mir. M. The Future of the City: Tall Buildings and Urban Design, WIT Press, Boston, 2013.

[8] A.Kiet. Arab Culture and Urban Form, Focus Journal, 2011. pp. 37-45.

[9] Ozgen, Aydan, Sev, Aysin. Innovations in Tall Buildings Construction in Turkey From Past to Present, CIB W065/055 Commissions : Transformation Through Construction, Dubai , 2008. pp.68-73.

[10] J. Craven. Jean Nouvel Buildings: Shadow \& Light .Architecture by Ateliers Jean Nouvel. [Electronic resource]. September 21, 2018.

[11] S.Al-Ahbabi and M.Al-Akili. Urban Vertical Design: The Impact of Tall Buildings on the Urban Structure of a City, Babylon University Journal, Engineering Sciences, 2013, № 3. P.1103.

[12] I. Al-Mandalawi, A.Hussein. Planning, Design and Technological Determinants of Tall Buildings. Master's thesis, Department of Architecture, College of Engineering, University of Baghdad, 1991.

[13] A. Mir and A.Ajla. Toward a Better Urban Life: Integration of Cities and Tall Buildings, Proceedings of the 4th Architectural Conference on the High-Rise, Amman, Jordan, 2008.

[14] National Report on Biodiversity in Iraq. Republic of Iraq, Ministry of Environment, July 2010. P 153.

[15] A.H. Taghlib, AlWaily. Baghdad 21st. Revival of Historical City. Turath, Monreal, Canada. 2017. P.106.

[16] http://www.alwasatnews.com/2678/news/read/358446/1.html

[17] https://issuu.com/turath/docs/part_2

[18] www.bureaubb.com/blog/istanbul 